\title{
THE CEMENTLESS PM HIP ARTHROPLASTY
}

\author{
FOUR-TO-SEVEN-YEAR RESULTS
}

MICHAEL DICKOB, THOMAS MARTINI

From the University of Ulm, Germany

We implanted 300 uncoated cementless PM prostheses into 271 patients and followed $251(\mathbf{9 2 . 6 \%})$ of them for four to seven years.

By then 37 had already been revised for aseptic and three for septic loosening. The survival rate with implant failure as the endpoint was $88.8 \%$ for the cup and $85.3 \%$ for the stem after six years. There was a higher risk of implant loosening in congenital dysplasia, unilateral hip arthroplasty and obesity.

The results of 225 unrevised hip replacements were assessed by questionnaire. Only $27.4 \%$ of the patients were completely free from pain and $17.9 \%$ had pain on walking any distance or at all times. The walking distance was for less than 30 minutes in $40 \%$.

Because of the poor results in comparison with other prostheses we do not recommend further use of the uncoated PM prosthesis.

J Bone Joint Surg [Br] 1996;78-B:195-9.

Received 22 September 1995; Accepted after revision 24 November 1995

Survivorship analysis of joint replacements, using removal of the implant as the endpoint, gives a reasonably objective evaluation of hip arthroplasties (Skeie et al 1991), but fails to provide information on unrevised prostheses (Johnston et al 1990; Liang et al 1991). The value of any follow-up study depends on reducing the number of cases lost to a minimum; this is often difficult to achieve (Dobbs 1980).

The cementless PM hip replacement (Aesculap Corporation, Tuttlingen, Germany) has been used throughout

M. Dickob, MD, Orthopaedic Surgeon

Bahnhofstrasse 30B, D-33602 Bielefeld, Germany.

T. Martini, MD, Dental Surgeon

Haupstrasse 19, D-87764 Legau, Germany.

Correspondence should be sent to Dr M. Dickob.

(c)1996 British Editorial Society of Bone and Joint Surgery 0301-620X/96/21169\$2.00
Europe (Refior et al 1988; Havelin et al 1993) but only the results of short-term studies have been published (Parhofer and Ungethüm 1984; Trepte and Gauer 1986; Wolf, Reichelt and Schlepckow 1988).

We now report our four-to-seven-year results with this prosthesis.

\section{PATIENTS AND METHODS}

Between October 1984 and May 1988 we implanted 300 cementless PM hip prostheses into 271 patients. There were 145 women and 126 men. Bilateral procedures were carried out on 17 women and 12 men. The average age at operation was 56.3 years for women (24 to 74 ) and 54.8 years for men (20 to 70); $95 \%$ of the patients were between 40 and 69 years of age. The primary diagnoses are listed in Table I.

Table I. Diagnoses, by percentage, in 271 patients who had a PM hip arthroplasty

\begin{tabular}{lcrc}
\hline Diagnosis & Female & Male & Total \\
\hline Primary osteoarthritis & 23.0 & 24.6 & 47.6 \\
Congenital dysplasia & 14.3 & 4.7 & 19.0 \\
Secondary osteoarthritis & 9.7 & 5.0 & 14.7 \\
(except congenital dysplasia) & & & \\
Osteonecrosis & 2.3 & 7.7 & 10.0 \\
Revision & 4.7 & 4.0 & 8.7 \\
\hline
\end{tabular}

All patients were operated on through an anterolateral approach without trochanteric osteotomy. The implants were inserted by five experienced orthopaedic surgeons (one consultant and four registrars) in a conventional operating theatre.

The PM hip prosthesis has a conical threaded acetabular component of cast titanium with a high-molecular polyethylene insert and a forged titanium-based stem (Ti6Al4V). Both the cup and the stem have a smooth surface without porous coating. The stem has a drop-shaped macrostructure on its anterior and posterior surfaces. A good press-fit fixation of the distal two-thirds of the stem should be achieved after reaming the medullary canal (Refior et al 1988). We used a modular head of aluminium oxide ceramic (Biolox, Feldmühle Corporation); $83 \%$ of the stems had a collar (Fig. 1). 


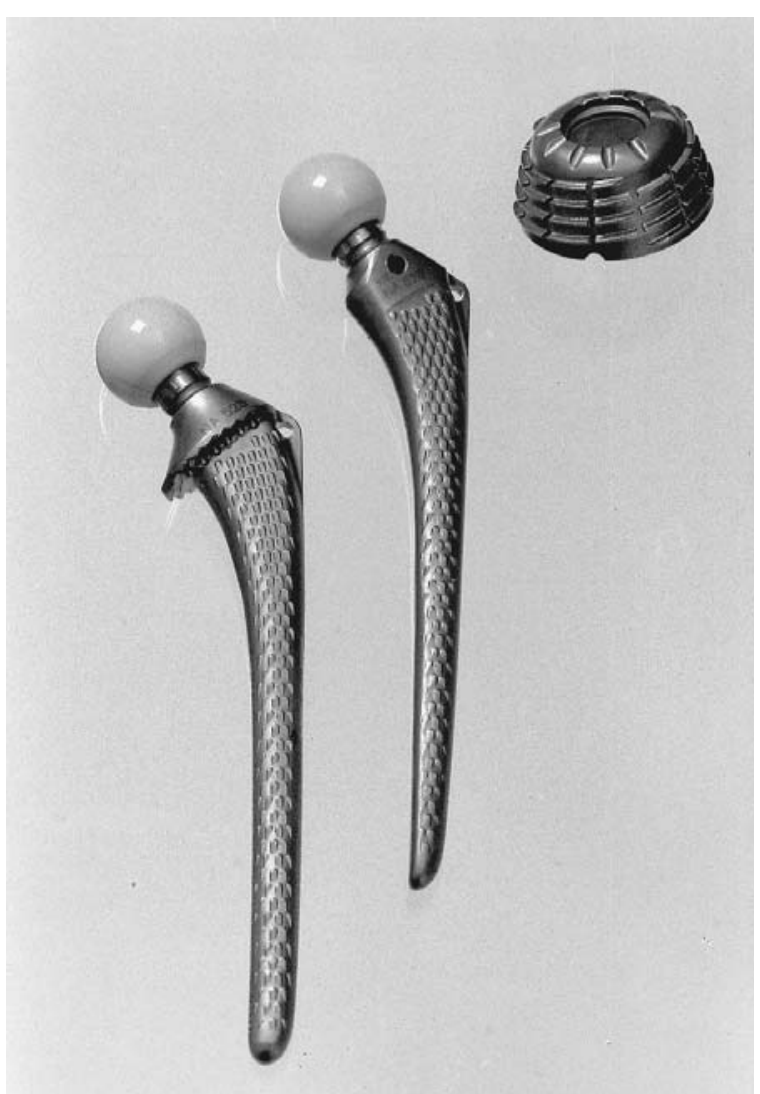

Fig. 1

The PM hip prosthesis has a conical-shaped threaded titanium cup and a smooth titanium-alloy stem with (left) or without a collar (right). questionnaires to be analysed. For survival analysis (Murray, Carr and Bulstrode 1993) a life table was constructed (Armitage 1971) and the standard error calculated (Greenwood 1926).

The body mass index (BMI) was calculated for all patients using the formula: weight in $\mathrm{kg}$ divided by height in $\mathrm{cm}-100$.

\section{RESULTS}

Analysis of revisions. Tables II and III are the life tables for cups and stems. There was a cumulative survivorship of $88.8 \%$ for the cups and $85.3 \%$ for the stems after six years. There were more than 50 cases entering the next interval. The standard error for these results was 0.020 for the cups and 0.022 for the stems. Figure 2 shows the survival curve.

Revision was required in 37 patients because of aseptic loosening and in three for septic loosening. Twenty-five patients needed removal of both components, 12 required revision of the stem only and three of the cup only. The mean revision rate at six years was $13.3 \%$.

Hips with congenital dysplasia showed a $17.5 \%$ risk for cup revision compared with $7.4 \%$ for other diagnoses after a primary hip arthroplasty (chi-squared test, $\mathrm{p}=0.02$ ). For stem revision, the rate was $21.1 \%$ for hips with dysplasia and $10.6 \%$ for all others (chi-squared test, $\mathrm{p}=0.04$ ).

In the 26 hips in which the implant was used at a revision operation only $7.7 \%$ required subsequent removal of the prosthesis compared with $13.9 \%$ of the primary hip replacements.

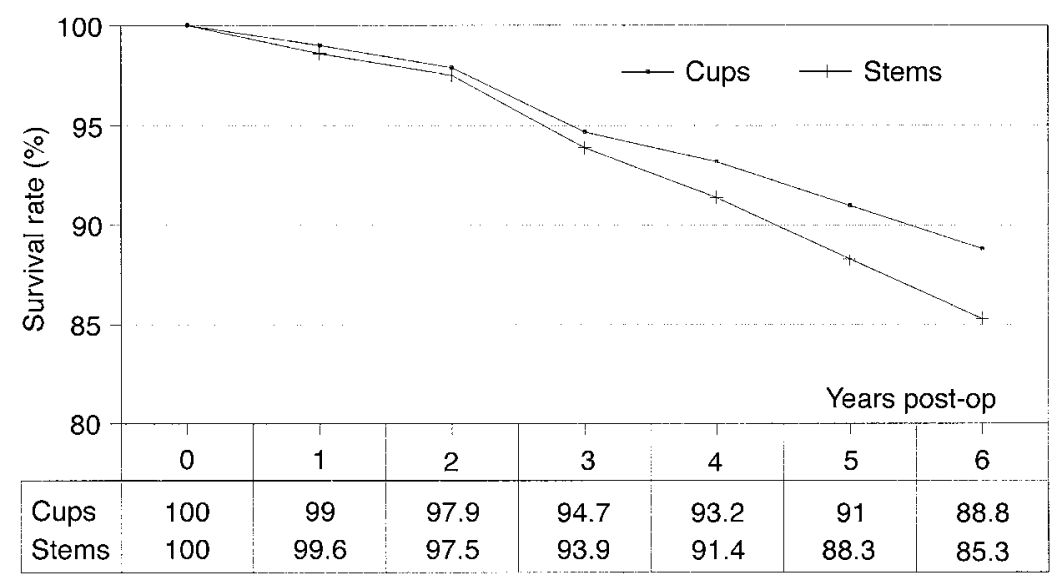

Fig. 2

Survival curve for the PM cup and stem. Standard errors are given in Tables II and III.

Clinical evaluation was performed by a questionnaire based on that of Johnston et al (1990) with an additional visual analogue scale. This was sent to all patients except for the 23 already revised in our hospital. Twenty patients were lost to follow-up, nine had died because of diseases unrelated to the hip arthroplasty, five with six implants were evaluated by telephone and 17 had undergone revision in other hospitals because of aseptic loosening, leaving 225
Unilateral replacement was associated with a more than twofold increase in the risk of implant failure compared with bilateral implantation $(15.6 \%$ v $6.7 \%$; chi-squared test, $\mathrm{p}=0.05)$.

There was a twofold increase in the incidence of loosening in patients who were overweight by $30 \%$ or more (BMI $>1.3$ ) compared with patients of normal weight $(\mathrm{BMI}=1.0$ $\pm 0.1)(19.4 \% \vee 10.2 \%$; chi-squared test, $\mathrm{p}=0.06)$. 

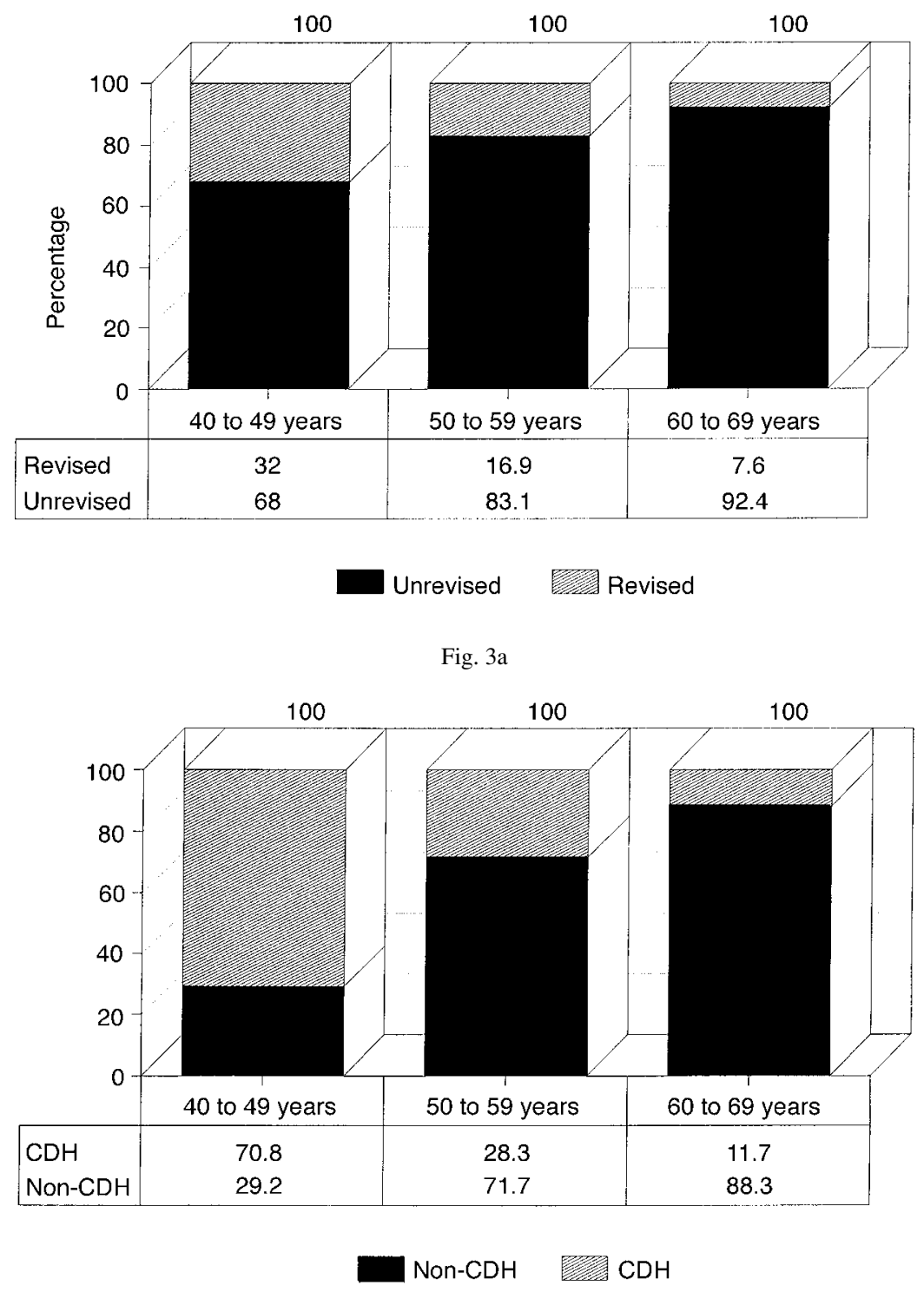

Fig. 3b

Figure $3 \mathrm{a}$ - Percentage of revised and unrevised PM arthroplasties in female patients related to age in years. Figure $3 b-$ Percentage of congenital dysplasia in female patients related to age in years. The high incidence of implant failure in young female patients is mainly produced by the number with congenital dysplasia.

In men there was no relation between age and the rate of revision, but women showed a strong association between age and the number of implant failures (chi-squared test, $p=0.01$; Fig. 3a). This was probably due to the highly significant relationship between $\mathrm{CDH}$ as the diagnosis with the highest risk of implant failure and the age of female patients ( $<<0.0001$; Fig. 3b).

We found no influence of cup or stem size or of neck length on prosthetic failure. Stems without a collar had a nearly twofold higher risk of removal than those with a collar $(21.6 \%$ v 11.6\%; chi-squared test, $\mathrm{p}=0.06)$.

Analysis of questionnaires. Analysis of the 225 questionnaires which were returned showed that $27.4 \%$ of patients had no pain, $35.6 \%$ had mild and occasional pain, $32.4 \%$ moderate pain and $4.6 \%$ severe pain. Pain occurred with the first steps in $31.4 \%$, when walking any distance in $14.3 \%$ and was present at all times in $3.6 \%$. Our analysis also showed that $5.5 \%$ of the patients were unable to put on their own shoes and socks and $10.9 \%$ had extreme difficulty in so doing. Although $84.6 \%$ could ascend and descend stairs normally or using a bannister, only $27.2 \%$ could get up from a chair without using the arms of the chair, and $3.6 \%$ always required assistance.

When walking $52.7 \%$ of the patients did not use any support, $31.3 \%$ used one cane only for long walks and $5.7 \%$ needed two crutches or a walker or were unable to 
Table II. Survival rates for the PM cup

\begin{tabular}{|c|c|c|c|c|c|c|c|c|c|}
\hline $\begin{array}{l}\text { Interval since } \\
\text { operation (yr) }\end{array}$ & $\begin{array}{l}\text { Number } \\
\text { at start }\end{array}$ & Failures & $\begin{array}{l}\text { Number } \\
\text { withdrawn }\end{array}$ & $\begin{array}{l}\text { Number } \\
\text { at risk }\end{array}$ & $\begin{array}{l}\text { Probability } \\
\text { of } \\
\text { survival }\end{array}$ & $\begin{array}{l}\text { Probability } \\
\text { of } \\
\text { failure }\end{array}$ & $\begin{array}{l}\text { Years } \\
\text { since } \\
\text { operation }\end{array}$ & $\begin{array}{l}\text { Cumulative } \\
\text { survival } \\
\text { rate }(\%)\end{array}$ & $\begin{array}{l}\text { Standard } \\
\text { error }\end{array}$ \\
\hline 0 to 1 & 300 & 3 & 14 & 293 & 0.990 & 0.010 & 0 & 100.0 & 0.000 \\
\hline 1 to 2 & 283 & 3 & 5 & 280.5 & 0.989 & 0.011 & 1 & 99.0 & 0.006 \\
\hline 2 to 3 & 275 & 9 & 1 & 274.5 & 0.967 & 0.033 & 2 & 97.9 & 0.008 \\
\hline 3 to 4 & 265 & 3 & 12 & 259 & 0.984 & 0.016 & 3 & 94.7 & 0.013 \\
\hline 4 to 5 & 250 & 5 & 74 & 213 & 0.977 & 0.023 & 4 & 93.2 & 0.015 \\
\hline 5 to 6 & 171 & 3 & 96 & 123 & 0.976 & 0.024 & 5 & 91.0 & 0.017 \\
\hline 6 to 7 & 72 & 2 & 68 & 38 & 0.947 & 0.053 & 6 & 88.8 & 0.020 \\
\hline 7 to 8 & 2 & & 2 & 1 & & & 7 & 84.1 & 0.030 \\
\hline
\end{tabular}

Table III. Survival rates for the PM stem

\begin{tabular}{|c|c|c|c|c|c|c|c|c|c|}
\hline $\begin{array}{l}\text { Interval since } \\
\text { operation (yr) }\end{array}$ & $\begin{array}{l}\text { Number } \\
\text { at start }\end{array}$ & Failures & $\begin{array}{l}\text { Number } \\
\text { withdrawn }\end{array}$ & $\begin{array}{l}\text { Number } \\
\text { at risk }\end{array}$ & $\begin{array}{l}\text { Probability } \\
\text { of } \\
\text { survival }\end{array}$ & $\begin{array}{l}\text { Probability } \\
\text { of } \\
\text { failure }\end{array}$ & $\begin{array}{l}\text { Years } \\
\text { since } \\
\text { operation }\end{array}$ & $\begin{array}{l}\text { Cumulative } \\
\text { survival } \\
\text { rate }(\%)\end{array}$ & $\begin{array}{l}\text { Standard } \\
\text { error }\end{array}$ \\
\hline 0 to 1 & 300 & 4 & 14 & 293 & 0.986 & 0.014 & 0 & 100.0 & 0.000 \\
\hline 1 to 2 & 282 & 3 & 5 & 279.5 & 0.989 & 0.011 & 1 & 98.6 & 0.007 \\
\hline 2 to 3 & 274 & 10 & 1 & 273.5 & 0.963 & 0.037 & 2 & 97.5 & 0.009 \\
\hline 3 to 4 & 263 & 7 & 12 & 257 & 0.973 & 0.027 & 3 & 93.9 & 0.014 \\
\hline 4 to 5 & 244 & 7 & 72 & 208 & 0.966 & 0.034 & 4 & 91.4 & 0.017 \\
\hline 5 to 6 & 165 & 4 & 93 & 118.5 & 0.966 & 0.034 & 5 & 88.3 & 0.019 \\
\hline 6 to 7 & 68 & 2 & 64 & 36 & 0.944 & 0.056 & 6 & 85.3 & 0.022 \\
\hline 7 to 8 & 2 & & 2 & 1 & & & 7 & 80.5 & 0.032 \\
\hline
\end{tabular}

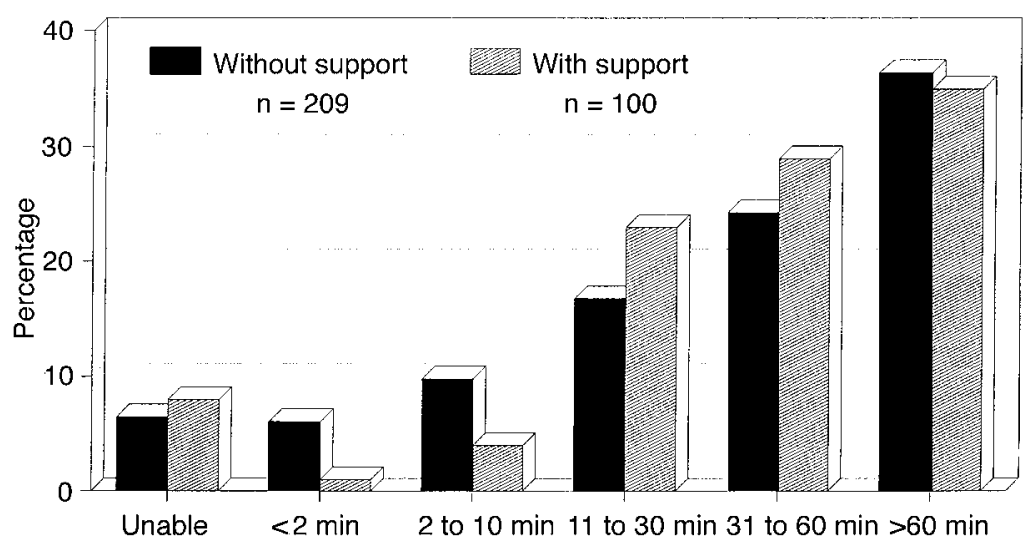

Fig. 4

Walking distances without and with support. Of the 225 patients, 118 did not use any support and therefore did not answer the question about walking distance with support. Eight were unable to walk even with support, two of whom were disabled by diseases unrelated to hip arthroplasty (Charnley category C).

walk. In only two patients was disability due to diseases unrelated to the hip arthroplasty. The walking distances with and without support are given in Figure 4. About $40 \%$ of patients had a walking distance of less than 30 minutes without support. According to their personal judgement only $19.5 \%$ of the patients had no limp without support.

Satisfaction with the result of the operation was expressed by $82.1 \%$ of the patients. There was no relation between satisfaction and length of time from operation. The result on the visual analogue scale was $71.8 \pm 27.3 \mathrm{~mm}$ (SD) 
for unilateral and $71.4 \pm 31.7 \mathrm{~mm}$ for bilateral hip replacement.

\section{DISCUSSION}

The use of a questionnaire with a standard system for reporting results (Johnston et al 1990) seems to be a costeffective method of outcome assessment. Of 260 unrevised patients $225(86.5 \%)$ returned their questionnaire. Other patients were contacted by telephone and only $7.4 \%$ were completely lost to follow-up. Questions concerning capacity for work were not answered by 45 of the 225 patients, but otherwise only $7 \%$ did not answer the questions fully.

The cumulative survivorship after six years, with over 50 cases still under review, was $88.8 \%$ for the PM cup and $85.3 \%$ for the stem. In a multicentre study Ahnfelt et al (1990) found the survival rate of cemented Stanmore and Charnley prostheses to be $89 \%$ to $92 \%$ after ten years. Skeie et al (1991) reported a 92\% survival rate for the Charnley replacement after 13 years. For the cementless Harris-Galante hip prosthesis a survival of about $97 \%$ at five years was reported by Martell et al (1993). Murray et al (1993) consider that standard implants currently have a failure rate of about $1 \%$ a year. Our results with the uncoated PM hip replacement after six years were discouraging.

There was a higher risk of aseptic loosening of the cup and stem in female patients with hip dysplasia. Patients who were overweight by more than $30 \%$ and/or had a unilateral replacement (Sutherland et al 1982) also had increased rates of failure. Revision procedures had a reduced risk of implant removal in comparison with primary arthroplasties, perhaps due to the lower physical activity of these patients (Harris and Maloney 1989). We did not find any relation between age and implant failure in men but in women there was an inverse correlation between age and revision rate caused by the greater number of $\mathrm{CDH}$ cases in younger patients.

More of our patients had a limp and were dissatisfied with the outcome of the operation compared with other reported series after uncemented replacements (Martell et al 1993). In a study of 126 patients with a cementless cup and a cemented stem, Harris and Maloney (1989) reported that only $6 \%$ of the patients had more than slight occasional discomfort and $30.1 \%$ had a limp; in our series $38 \%$ suffered from moderate or severe pain and $80.5 \%$ had a limp.

The main problem with the design of the PM hip seems to be the smooth surface of the cup and stem which makes ingrowth of bone impossible. It is also doubtful whether long-term press-fit fixation is achievable. In 1988 a new design of stem was introduced with a porous coating on the proximal third of the shaft (Refior et al 1988). No results have yet been published for this modification.

No benefits in any form have been received or will be received from a commercial party related directly or indirectly to the subject of this article.

\section{REFERENCES}

Ahnfelt L, Herberts P, Malchau H, Andersson GBJ. Prognosis of total hip replacement: a Swedish multicenter study of 4,664 revisions. Acta Orthop Scand 1990;61 Suppl 238:1-26.

Armitage P. Statistical methods in medical research. New York: Wiley, 1971:409-12.

Dobbs HS. Survivorship of total hip replacements. J Bone Joint Surg [Br] 1980;62-B:168-73.

Greenwood M Jr.Appendix I. The "errors of sampling" of the survivorship tables. In: A report on the natural duration of cancer. London: HMSO, 1926. Reports on Public Health and Medical Subjects No 33.

Harris WH, Maloney WJ. Hybrid total hip arthroplasty. Clin Orthop 1989;249:21-9.

Havelin LI, Espehaug B, Vollset SE, Engesaeter LB, Langeland N. The Norwegian arthroplasty register: a survey of 17444 hip replacements 1987-1990. Acta Orthop Scand 1993;64:245-51.

Johnston RC, Fitzgerald RH, Harris WH, et al. Clinical and radiographic evaluation of total hip replacement: a standard system of terminology for reporting results. J Bone Joint Surg [Am] 1990;72-A:161-8.

Liang MH, Katz JN, Phillips C, et al. The total hip arthroplasty outcome evaluation form of the American Academy of Orthopaedic Surgeons. $J$ Bone Joint Surg [Am] 1991;73-A;639-46.

Martell JM, Pierson RH III, Jacobs JJ, et al. Primary total hip reconstruction with a titanium fiber-coated prosthesis inserted without cement. J Bone Joint Surg [Am] 1993;75-A:554-71.

Murray DW, Carr AJ, Bulstrode C. Survival analysis of joint replacements. J Bone Joint Surg [Br] 1993;75-B:697-704.

Parhofer R, Ungethüm M. Experiences with hip joint endoprosthesis model PM for cement free implantation. Z Orthop 1984;122:790-7.

Refior HJ, Parhofer R, Ungethüm M, Blömer W. Special problems of cementless fixation of total hip-joint endoprostheses with reference to the PM type. Arch Orthop Trauma Surg 1988;107:158-71.

Skeie S, Lende S, Sjoberg EJ, Vollset SE. Survival of the Charnley hip in coxarthrosis: a 10-15 year follow-up of 629 cases. Acta Orthop Scand 1991;62:98-101.

Sutherland CJ, Wilde AH, Borden LS, Marks KE. A ten-year followup of one hundred consecutive Müller curved-stem total hip-replacement arthroplasties. J Bone Joint Surg [Am] 1982;64-A:970-82.

Trepte CT, Gauer EF. Initial experiences with the cementless PM endoprosthesis. Z Orthop 1986;124:636-42.

Wolf T, Reichelt A, Schlepckow P. Clinical results using the PM type of hip endoprosthesis. Z Orthop 1988;126:637-42. 